\title{
AISLAMIENTO E IDENTIFICACIÓN DE Moniliophthora roreri CAUSANTE DE LA MONILIASIS EN MUNICIPIOS DEL NORORIENTE COLOMBIANO Y ENSAYOS PRELIMINARES PARA SU CONTROL BIOLÓGICO
}

Por:

Liliana Yanet Suárez Contreras?

\section{RESUMEN}

Este proyecto de investigación definió las zonas de influencia de la moniliasis. Se aisló e identificó el hongo Moniliophthora roreri causante de la enfermedad. Se obtuvieron 56 muestras en: Agua Clara, Tibú, Sardinata, El Tarra, Bucarasica, El Zulia, Teorama y Cúcuta en el Nororiente Colombiano. Se identificó el hongo a nivel morfológico por medio de montajes en el microscopio. Confirmada la presencia del hongo, las muestras se conservaron en placas con agar papa dextrosa. Se realizaron pruebas preliminares de inhibición antagónica mediante la técnica lgarashi con Trichoderma sp. El Zulia, Trichoderma sp. Iscalá y Trichoderma sp. de Cuba, donde se evidenció la posibilidad de controlar biológicamente al fitopatógeno Moniliophthora roreri. Se obtuvieron resultados preliminares favorables del 55\% de inhibición antagónica. También se realizaron aislamientos de seis nuevas cepas de Trichoderma sp. y un Bacillus sp.

Palabras claves: Moniliasis, Moniliophthora roreri, biocontrol, antagonismo, aislamiento de hongos.

\section{ABSTRACT}

This proyect of researching defines the influence zones of the Moniliasis. In this project was isolated and identified the Moniliophthora roreri, the disease is caused by this fungus. 56 samples were goteen in Agua Clara, Tibú, Sardinata, El Tarra, Bucarasica, El Zulia, Teorama and Cúcuta in the Colombia Nororiente. The fungus was identified in a morphological level by means of microscopical test, the samples were conserved on the plates, added potato dextrose agar. Preliminary of antagonistic inhibition though the Igarashi technique, they were made on Trichoderma sp. El Zulia, Trichoderma sp. Iscalá, Trichoderma sp. of Cuba, where it was demonstrated that the controlling biological of phytopathogen Moniliophthora roreri. Finally, 55\% of results were obtained from antagonistic inhibition. Also, the isolations of six new stocks of Trichoderma sp. were made, and a Bacillus sp. too.

\section{INTRODUCCIÓN}

La Moniliasis es una enfermedad que produce las mayores pérdidas de cacao en Colombia. Un 30\% de la cosecha anual, valorada en mil ciento sesenta millones de pesos, se pierde (Federación Nacional de Cacaoteros, 2004).

Al comienzo de la enfermedad, las mazorcas presentan una o más manchas de color claro con bordes bien definidos; luego un polvo blanco cubre el fruto; por último, el color blanco cambia a crema. El hongo llega fácilmente a árboles sanos por acción del viento, el agua, los insectos, los animales, y el hombre (Suárez, 2004; Barros, 1977; Campuzano, 1980; Cubillos, 1970). Según la Federación Nacional de Cacaoteros, 2004, el ataque del hongo es mayor en climas húmedos de alta temperatura.

El presente trabajo tiene como objetivo el estandarizar una metodología de aislamiento del hongo Moniliophthora roreri e identificar las muestras de los municipios y corregimientos de mayor presencia de moniliasis. Se aislaron cepas en Agua Clara, Tibú, Sardinata, El Tarra, Bucarasica, El Zulia, Teorama y Cúcuta. Así se estableció el primer banco de cepas de Moniliophthora roreri del Nororiente Colombiano.

La Universidad Francisco de Paula Santander, específicamente, el grupo de investigación Ambiente

\footnotetext{
Lic. Biología-Química, MSc. Biología énfasis genética. Candidata a Doctor en Biotecnología. Departamento de Biología de la Universidad Francisco de Paula Santander. Profesora de tiempo completo. Coordinadora del laboratorio de Genética Molecular. Universidad Francisco de Paula Santander. lysuarez@bari.ufps.edu.co
} 
Aislamiento e identificación de Moniliophthora roreri causante de la moniliasis en municipios del Nororiente Colombiano y ensayos preliminares para su control biológico.

y Vida, ha planteado y formulado una serie de investigaciones dirigidas hacia la cadena productiva del cultivo de cacao, entre las que sobresale el aislamiento y la identificación del hongo Moniliophthora roreri.

Hasta el momento el control de la moniliasis ha sido con prácticas de cultivo. Se han realizado trabajos de control biológico, genético y químico (Merchán, 1981). En la investigación se realizaron ensayos preliminares de antagonismo frente a Trichoderma sp. con resultados favorables para el control biológico de la enfermedad.

\section{MATERIALES Y MÉTODOS}

Toma de muestras.

Se hizo la selección de muestras en cada zona afectada con los síntomas de Moniliophthora roreri. Las mazorcas de cacao fueron recolectadas y conservadas en bolsas de manila a temperatura ambiente. Se registraron los datos del municipio, del propietario de la finca, altitud, temperatura, condiciones climáticas, información sobre el cultivo y daños con la colaboración de los técnicos de la Federación Nacional de Cacaoteros del Norte de Santander. Luego se trasladaron al Laboratorio de Microbiología y Genética Molecular de La Universidad Francisco de Paula Santander.

Las muestras se tomaron según el porcentaje de incidencia de Moniliophthora roreri, en Agua Clara, Tibú, Sardinata, El Tarra, Bucarasica, El Zulia, Teorama y Cúcuta.

\section{Aislamiento.}

Se realizó la metodología de aislamiento propuesta por Barros y Sánchez (1979). Se utilizó el método de desinfección superficial de la mazorca en alcohol al $40 \%$ un minuto y posteriormente, con hipoclorito de sodio al $1 \%$ durante un minuto. Se frotó la mazorca, y luego se lavó con alcohol y flameó. Después de esta desinfección, se cortaron pequeños trozos y se desinfectaron con hipoclorito al $1 \%$ durante un minuto y se transfirieron a medio PDA. Las placas se mantuvieron a $28^{\circ} \mathrm{C}$. Otro método fue similar al anterior, pero se diferencia en que los trozos de tejido enfermo, se sembraron directamente en el medio sin más desinfección.

El último método aplicado fue una modificación de los anteriores donde los aislamientos se realizaron a partir de mazorcas infectadas por Moniliophthora roreri tomando trozos de $2 \mathrm{~cm} \times 2 \mathrm{~cm}$, los cuales se lavaron con agua para más tarde ser expuestos a agentes desinfectantes como hipoclorito de sodio al 2,5 y $3 \%$, durante 2 minutos, y alcohol al 60\% durante 3 minutos. Posteriormente se sembraron cuatro trozos en caja Petri en medio (PDA) con un tiempo de incubación de 10 días a $28^{\circ} \mathrm{C}$.

\section{Medio Nutritivo.}

Se evaluaron tres medios nutritivos: agar papa dextrosa, agar sabouraud y agar avena, realizando tres tratamientos por medio nutritivo, se determinó la velocidad de crecimiento, en diámetro micelial durante doce días, evaluando cada tres, seis y doce días de incubación.

\section{Identificación.}

La identificación fue realizada por montajes al microscopio. Se observaron características macroscópicas y microscópicas, empleando la metodología de tinción simple con el colorante azul de lacto fenol, colocando parte del micelio del hongo sobre un portaobjetos adicionando el colorante. Se evaluó la presencia de estructuras septadas, moniliformes, conidias hialinas brillantes, heteromorficos bi o trifurcados en su base, con un micelio corto y entreverado en sus puntas (Suárez, 2004). 
Aislamiento e identificación de Moniliophthora roreri causante de la moniliasis en municipios del Nororiente Colombiano y ensayos preliminares para su control biológico.

Conservación de los aislamientos.

La conservación de los aislamientos se realizó en el medio nutritivo PDA en cajas de Petri previamente esterilizadas.

\section{Pruebas de antagonismo.}

Para las pruebas de antagonismo se utilizaron cepas de Trichoderma sp. de origen nativo: El Zulia e Iscalá y una cepa de origen Cubano, pertenecientes al cepario de la Universidad Francisco de Paula Santander. Se empleó para la siembra la técnica de lgarashi en medio nutritivo (Villavicencio, 2004)

\section{Aislamiento de otras cepas de Trichoderma sp.}

Se aislaron seis nuevas cepas de Trichoderma sp a partir de suelos de cultivos de cacao. Se hicieron diluciones seriadas de $10^{-1}$ hasta $10^{-4}$ en agua peptona, tomando 10 gramos de muestra en $99 \mathrm{ml}$ de agua peptona. De cada tubo se tomaron 0,1 $\mathrm{ml}$ de muestra que fue inoculada en medio nutritivo y agar celulosa. Incubados a $25^{\circ} \mathrm{C}$. Se aisló un Bacillus sp. en agar LB, de interés para control biológico conservado a $32^{\circ} \mathrm{C}$.

\section{RESULTADOS Y DISCUSIONES}

En cuanto al aislamiento de Moniliophthora roreri, (Figura 1 y Figura 2) el protocolo propuesto por Barros y Sánchez (1979), fue el más apropiado, aunque se presentaron algunas dificultades para su cultivo puro bajo condiciones de laboratorio. Un inconveniente observado es que el crecimiento del hongo en PDA es muy lento y algunos contaminantes como: Aspergillus sp. Fusarium sp. y levaduras impiden su desarrollo. En otros casos aunque el tejido mostraba el síntoma de la enfermedad, al hacer la desinfección no se presentó crecimiento y en otras se desarrolló abundantemente, esta variabilidad dificulta el estudio del patógeno en el laboratorio (Barros y Sánchez, 1979). Aunque la lentitud de su crecimiento en PDA ha sido una gran ventaja para la conservación de las cepas.
Fig 1. Moniliophthora roreri en mazorcas de Theobroma cacao.

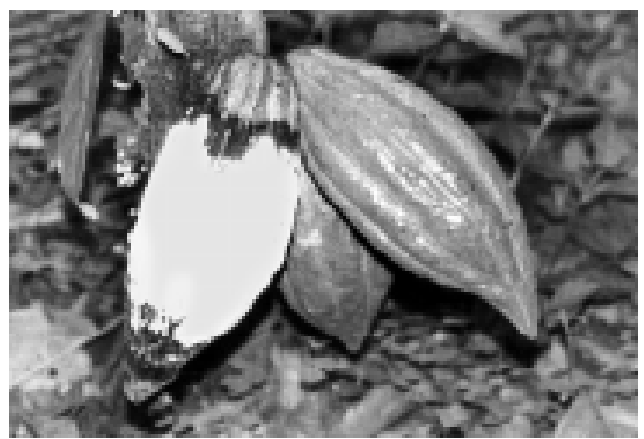

Fuente: autor del trabajo. Foto por Stella Monsalve.

Fig.2. Estados iniciales de Infección Moniliophthora roreri

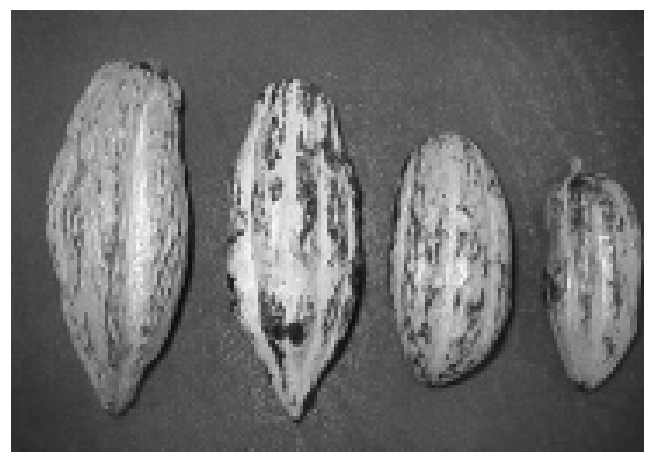

Fuente: autor del trabajo. Foto por Darwin Martínez.

De los métodos utilizados el más efectivo fue el de la desinfección superficial de la mazorca (figura 3).

Figura 3. Moniliophthora roreri en medio PDA.

A Cepa izquierda de 15 días de crecimiento y Cepa derecha de 10 días de crecimiento.

B Cepas de 20 días de crecimiento.

A

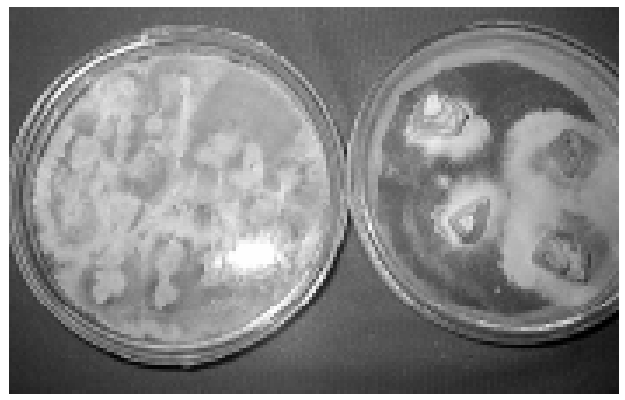

Fuente: autor del trabajo y Darwin Martínez. 
Aislamiento e identificación de Moniliophthora roreri causante de la moniliasis en municipios del Nororiente Colombiano y ensayos preliminares para su control biológico.

B

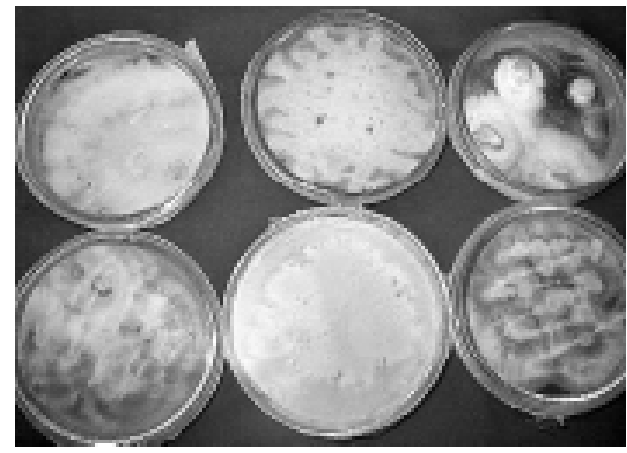

Fuente: autor del trabajo y Darwin Martínez.

El crecimiento del hongo es radial en los tres medios de cultivo. Moniliophthora roreri en PDA necesitó de 22 días para cubrir el medio totalmente y presentó el desarrollo micelial característico. En agar sabouraud, el hongo creció en 15 días, indicando que el hongo puede crecer y esporular en estos medios de cultivo artificiales pero con más lentitud (Barros 1977; Arguello 1990).

De los tres tratamientos evaluados por medios nutritivos, se registró el crecimiento micelial por diámetro de micelio cada tres, seis y doce días de incubación a $28^{\circ} \mathrm{C}$ en cámara de incubación donde Moniliophthora roreri mostró un crecimiento micelial de 3,5 cms de diámetro en 10 días de incubación; se evidencia el medio nutritivo de agar papa dextrosa como el óptimo para su crecimiento (Figura 3).

Las características macroscópicas observadas por Castaño (1952) fueron confirmadas al observar el crecimiento zonal en áreas concéntricas con tonalidad variable dentro de la colonia. El centro pardo oscuro, con una masa conidial pulverulenta dispuesta en una capa compacta contiguamente a una zona color crema, salpicada con masa conidial. La zona micelial formada por filamentos cortos y entreverados y de color blanco al principio y luego crema (Castaño, 1952; Cubillos, 1970; Barros 1977; Suárez 2004).

Teniendo en cuenta las características microscópicas, se confirma el trabajo de Arguello 1990: Conidias globosas, hifas y conidias hialinas durante su estado joven; micelio hialino y brillante (Guarín y Pacheco 1990). Las esporas son globosas, subglobosas y elípticas (Evans, 1981; Suárez 2004). (Figura 4).

Moniliophthora roreri pertenece a la división mychota, subdivisión Eumycotina, clase Basidiomycetos especie Crinipellis, variedad roreri, (Evans 2003).

Figura 4. Micelio de Moniliophthora roreri al microscopio

A Micelio e Hifas de Moniliophthora roreri al microscopio. $40 \times$

A

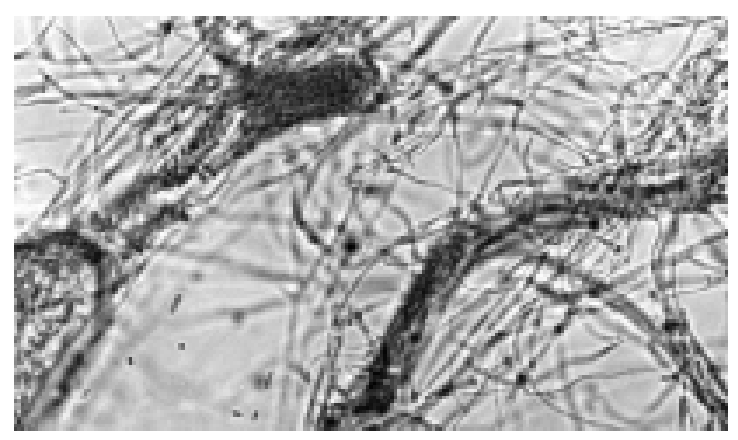

Fuente: autor del trabajo. Foto por Margarita Caballero

B Esporas o Conidias de Moniliophthora roreri al microscopio $100 x$

B

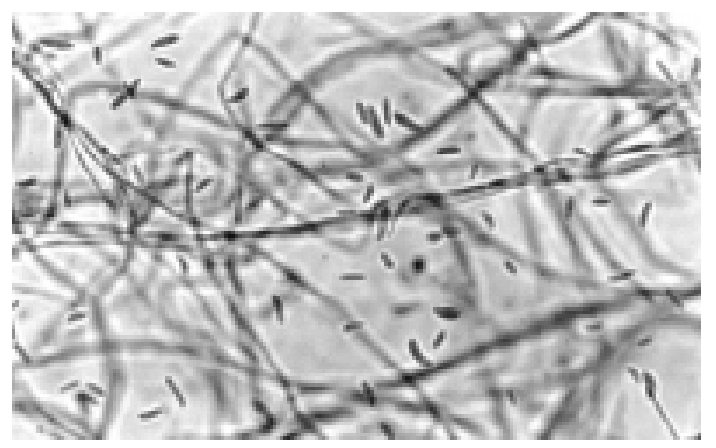

Fuente: autor del trabajo. Foto por Margarita Caballero

Después de estandarizar el protocolo de aislamiento para el fitopatógeno de los municipios muestreados, se lograron obtener 56 aislamientos de Moniliophthora 
Aislamiento e identificación de Moniliophthora roreri causante de la moniliasis en municipios del Nororiente Colombiano y ensayos preliminares para su control biológico.

roreri provenientes de mazorcas infectadas por el hongo (figura. 1). La mayor incidencia de la moniliasis estuvo en los municipios donde se hizo mayor recolección de muestras (Tabla 1).

Tabla 1. Aislamientos de Moniliophthora roreri en el Nororiente Colombiano.

\begin{tabular}{|l|c|l|}
\hline \multicolumn{1}{|c|}{ Municipio } & $\begin{array}{c}\text { Número de } \\
\text { aislamientos }\end{array}$ & \multicolumn{1}{|c|}{ Nombre de la finca } \\
\hline Bucarasica & 11 & Miraflores, San isidro, Porvenir. \\
\hline El Tarra & 8 & Manzanares \\
\hline El Zulia & 8 & Brisas del Zulia y Perla \\
\hline Cúcuta & 7 & San Isidro, Lote Vegas \\
\hline Sardinata & 6 & La Piñuela, los cocos \\
\hline Agua Clara & 6 & Jardín clonal, la fortuna \\
\hline Tibú & 5 & Buenos Aires \\
\hline Teorama & 5 & San Roque \\
\hline Total & 56 & \\
\hline
\end{tabular}

Fuente: autor del trabajo.

Los bioensayos realizados con Trichoderma sp. han sido efectivos (Evans, 1981; Krauss y Soberanis, 2001) indicando que el control biológico es un método muy efectivo y económico seguido por el control cultural (Krauss y Soberanis, 2002). Los resultados obtenidos durante la prueba de antagonismo fueron de una inhibición del crecimiento de Moniliophthora roreri en un $95 \%$ frente a la siembra con la cepa de Trichoderma sp. del Zulia, indicando que puede ser un posible controlador biológico para la moniliasis; la respuesta presentada frente a la cepa Trichoderma sp. de Iscalá fue del $70 \%$ y la de la cepa Trichoderma sp. Cubana fue de un 55\%, estos valores de inhibición por encima del $50 \%$ los convierten también en posibles controladores biológicos (figura 5).

Por lo tanto se continuará con un nuevo proyecto para probar la respuesta de todos los aislamientos de Moniliophthora roreri realizados en este trabajo frente a las seis nuevas cepas de Trichoderma sp. aisladas en el laboratorio, haciendo los respectivos ensayos in vitro.

Bravo, y Victoria, en 1981 estudiaron la posibilidad de utilizar control biológico de la moniliasis bajo condiciones de laboratorio, indicando que el género Bacillus puede inhibir Moniliophthora roreri in vitro e

in vivo, este es otro ensayo que se realizará con el Bacillus aislado en el laboratorio.

Figura 5. Pruebas de Antagonismo con cepas de Trichoderma sp. A Trichoderma sp. de origen Cubano

B Trichoderma sp. de Iscalá

C Trichoderma sp. de El Zulia

A
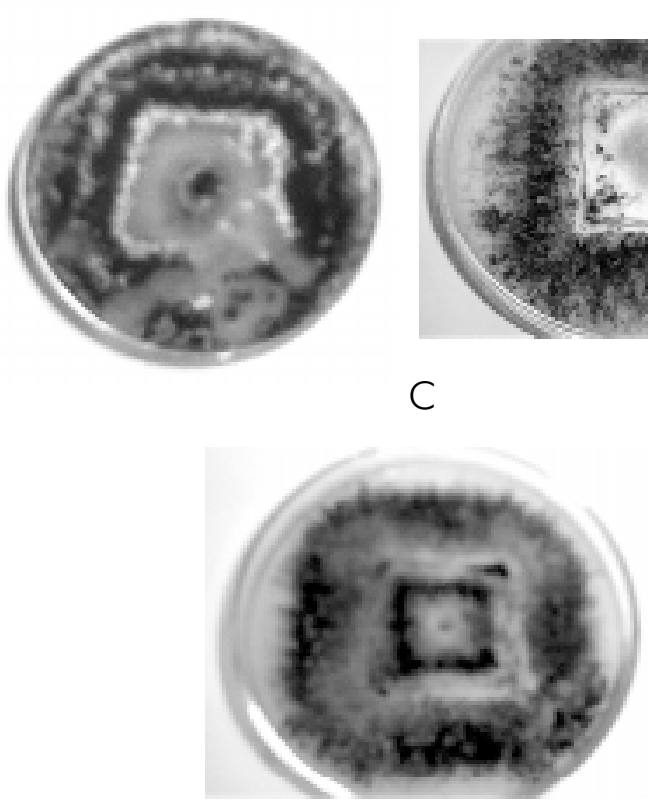

Fuente: Autor del trabajo y Manuel Villavicencio.

\section{CONCLUSIONES}

El presente trabajo ha permitido estandarizar un protocolo de aislamiento para Moniliophthora roreri en condiciones in Vitro. Se ha determinado que el tiempo de incubación de Moniliophthora roreri es de 10 días a $28^{\circ} \mathrm{C}$ en cámara de incubación. Se comprobó que el medio nutritivo donde presenta mayor eficiencia en crecimiento miceliar, Moniliophthora roreri fue agar papa dextrosa.

También se logró aislar e identificar 56 muestras de Moniliophthora roreri pertenecientes a los municipios y corregimientos de: Agua Clara, Tibú, Sardinata, El Tarra, Bucarasica, El Zulia, Teorama y Cúcuta del Nororiente Colombiano. 
Aislamiento e identificación de Moniliophthora roreri causante de la moniliasis en municipios del Nororiente Colombiano y ensayos preliminares para su control biológico.

En los ensayos de antagonismo, la cepa de Trichoderma sp. de El Zulia mostró una inhibición de Moniliophthora roreri del 95\%.

\section{AGRADECIMIENTOS}

Al Fondo de investigaciones Universitarias (FINU) Universidad Francisco de Paula Santander por el apoyo financiero. A través del proyecto 016-2003.

A FEDECACAO- Norte de Santander, por facilitar el soporte técnico y las muestras de Moniliophthora roreri.

A Darwin Hernando Martínez Botello y Andrea Lorena Rangel Silva, estudiantes de Ingeniería Biotecnológica, por su colaboración en los aislamientos de Moniliophthora roreri y Trichoderma sp.

Al Ing. Manuel Villavicencio, por su colaboración en las pruebas de antagonismo.

\section{BIBLIOGRAFÍA}

ARGUELLO, O. 1990. Seminario Nacional de Actualización en Cacao con énfasis en la rehabilitación de plantaciones. Ministerio de Agricultura, Instituto Colombiano agropecuario. Subgerencias de Transferencia de Tecnología y de Investigación, ICA. Manizales, noviembre 27-29.

BARROS, O. 1977. Investigaciones sobre el hongo Monilia roreri, Cif y Par, causante de la pudrición Acuosa de la mazorca del cacao: sus daños y su control, el cacaotero Colombiano, No. 3, 42-43p, diciembre.

BARROS, O.; SÁNCHEZ, J. 1979. Un método de aislamiento del hongo Monilia roreri, Cif y Par. Información técnica. El cacaotero Colombiano. No. 11, diciembre.

BRAVO, N.; VICTORIA, K. 1981. Posibilidades del control biológico de la moniliasis (Moniliophthora roreri Evans) del cacao (Theobroma cacao L.) Acta Agron. 31 , 133-141 p.
CASTAÑO, J.J. 1952. Moniliasis del cacao en una región del departamento de Caldas, Agricultura tropical, 6, 21-25 p.

CUBILLOS, G. 1970. Monografía sobre la moniliasis. Caldas, Colombia, Universidad de Caldas, 37 p.

EVANS, H. 1981. Pod rot of cocoa caused by Moniliophthora roreri. Phytopathol papers, 24.

-2001. Biocontrol of cocoa pod diseases with mycoparasite mixtures. Biol. Control, 22, 149-158 p.

EVANS, H.; KEITH, H.; THOMAS, S.; ARROYO C. 2003. Field screening in Costa Rica of Ecuatorian mycoparasites of the cocoa frosty pod rot pathogen Crinipellis (Moniliophthora) roreri. CABI Bioscience UK, CATIE, Turrialba, Costa Rica. 143 p.

www.copal-cpa.org.

MERCHÁN, V. 1981. Avances en la investigación de la Moniliasis del Cacao en Colombia. El cacaotero Colombiano, No.16, 26-41.

SUÁREZ, C. 1971. Estudio del mecanismo de penetración y del proceso de infección de Monilia roreri Cif y Par. En frutos de cacao (Theobroma cacao). Tesis, Guayaquil.

SUÁREZ, L. 2004. Aislamiento e identificación del hongo Moniliophthora. roreri a partir de Cultivos de cacao ubicados en Norte de Santander-Colombia. Sevilla, España. Tesina.

VILLAVICENCIO, M. F.; MARTíNEZ, L. C. 2004. Evaluación y aplicación de Trichoderma harziano como antagonista y promotor de crecimiento vegetal en tomate y pimiento. Tesis.

Fecha recibido: Octubre 13 de 2005

Fecha aceptación: Mayo 30 de 2006 